\title{
THE ELECTRON MICROSCOPY OF ENDOCARDIAL FIBROELASTOSIS*
}

\author{
BY \\ W. J. S. STILL and E. H. BOULT \\ From the Departments of Pathology and Physical Chemistry, University of Durham
}

(RECEIVED FOR PUBLICATION FEBRUARY 11, 1957)

It has been shown (Still and Boult. 1956) that when teased preparations of the endocardium in congenital endocardial fibroelastosis are studied by electronmicroscopy the superficial zones are largely composed of a material bearing little resemblance to collagen or elastic tissue, as the histological appearances suggest, but having the morphological characters of fibrin. We proposed therefore that this material's presence must be due to the incorporation of surface deposits into the endocardium.

Teased preparations cannot, however, represent accurately either the exact position of fibres, or their relative amount in the endocardium, and only thin sections can do this satisfactorily. A study of such sections is described in this communication, and it seems to bear out our previous conclusions.

\section{Material and Methods}

The left ventricular endocardium from seven infants aged 6 to 9 months with diffuse endocardial fibroelastosis were examined. From each heart a $1 \mathrm{~mm}$. cubed block of endocardium from the surface area was taken (Fig. 1). The blocks were treated with $1 \%$ buffered osmic acid as an electron stain, and embedded in a mixture of butyl and methyl metacrylate. The blocks were sectioned on a Cook and Perkins ultramicrotome with a heat-expanding object arm, and in general the sections used for viewing were in the region of 300 to $400 \mathrm{~A}^{\circ}$ in thickness $\left(10,000 \mathrm{~A}^{\circ}=1 \mu\right)$. Photographs were taken at magnifications of between 6,000 and 9,000 times and enlarged photographically.

\section{Controls}

Before examining the pathological endocardium by electron microscopy, it was necessary for comparison to ascertain the appearances of collagen, elastic tissue and fibrin in ultra-thin sections. Fig. 2 is a thin section of a child's aorta, in which collagen and elastic tissue are shown. The collagen is seen as clearly defined individual fibrils about 800 to $900 \mathrm{~A}^{\circ}$ wide and showing periodic

- Read at a conference of the Pathological Society of Great Britain in January, 1957. cross striations at $640 \mathrm{~A}^{\circ}$ intervals. The elastic tissue is represented by the wide dark-staining band, with no apparent periodic cross striation or fibrillary pattern. These appearances are not essentially different from what is seen in our own teased preparations and moreover they answer to the recognized description of collagen and elastic tissue (Gross and Schmitt, 1948; Hall, Reed and Tunbridge, 1955).

The electron microscopic appearances of fibrin, in teased form, have been defined by Hawn and Porter

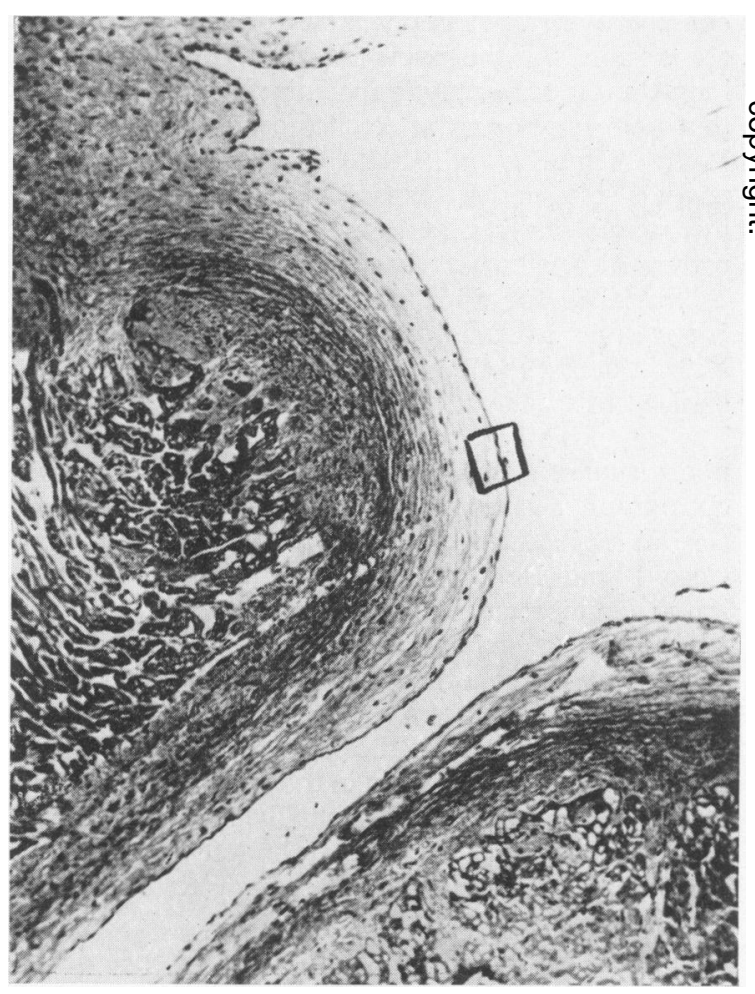

FIG. 1.-Paraffin section of endocardium. The area investigated by electron microscope is marked thus $\square$. Haematoxylin and eosin. $\times 125$. 


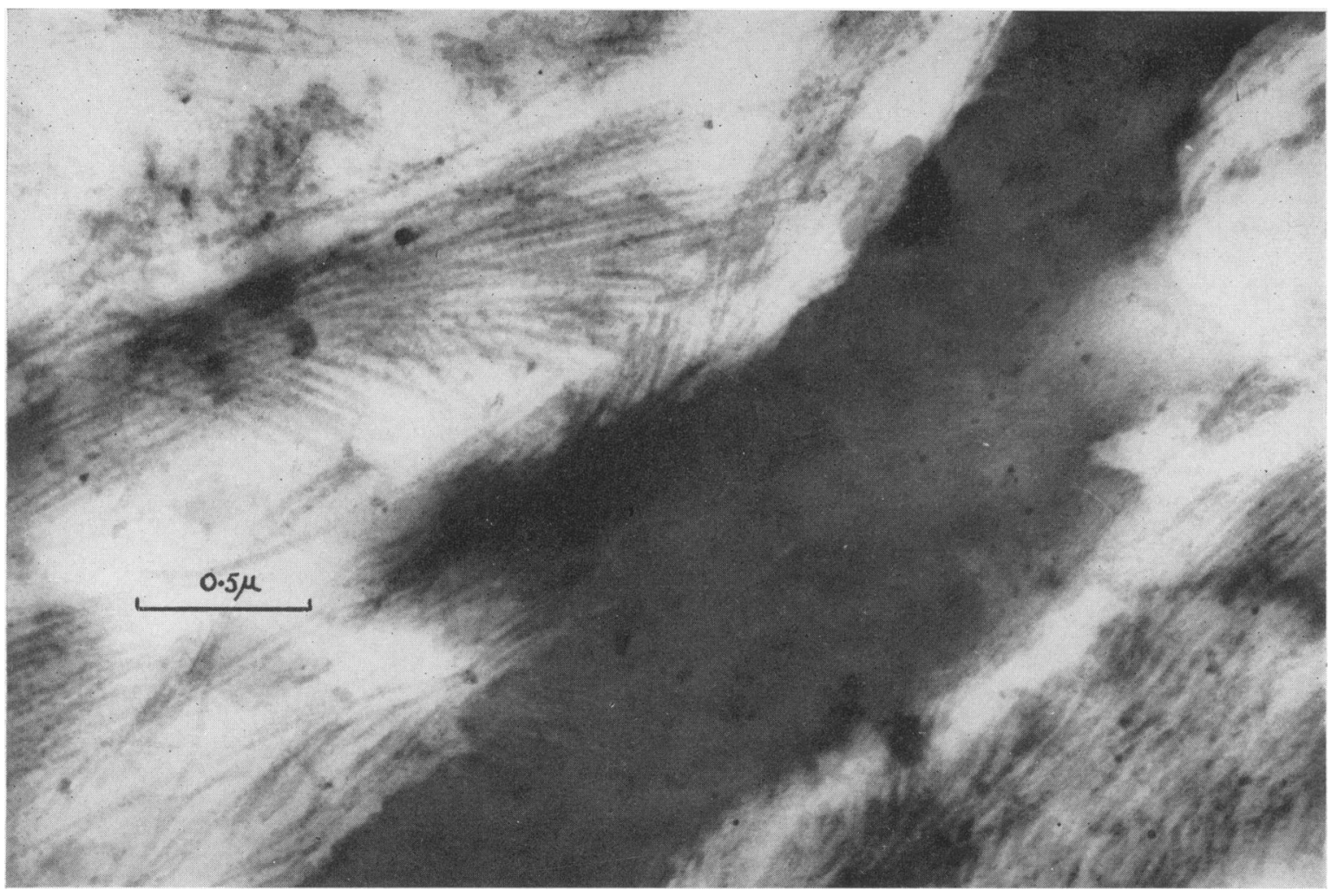

FIG. 2.-Thin section of child's aorta, showing collagen and elastic tissue. $\times 30,000$.

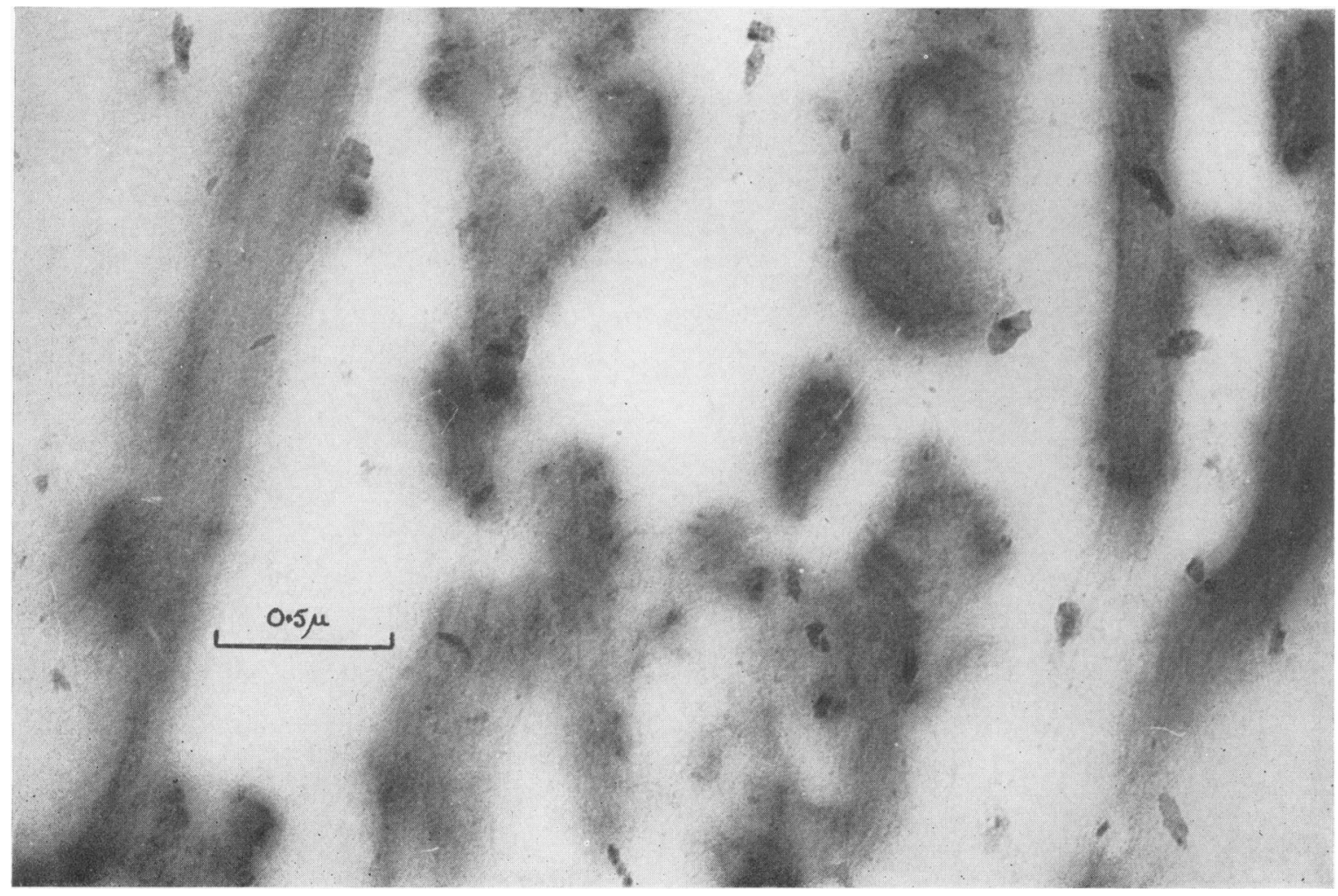

Fig. 3.-Common appearance of known fibrin in a thin section of inflammatory exudate. $\times 45,000$. 


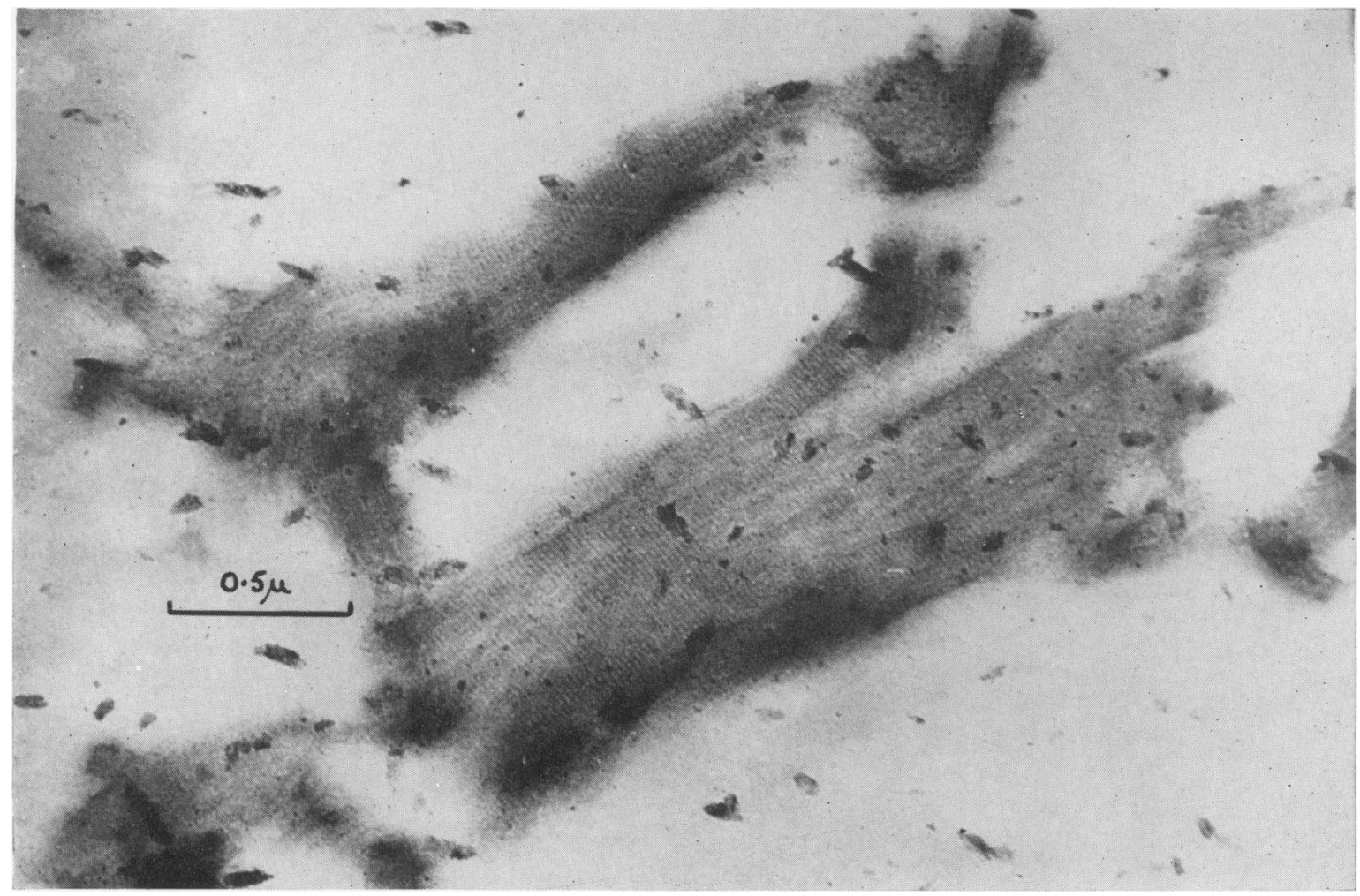

Fig. 4. - Striated appearance of fibrin from inflammatory exudate. $\times 45,000$.

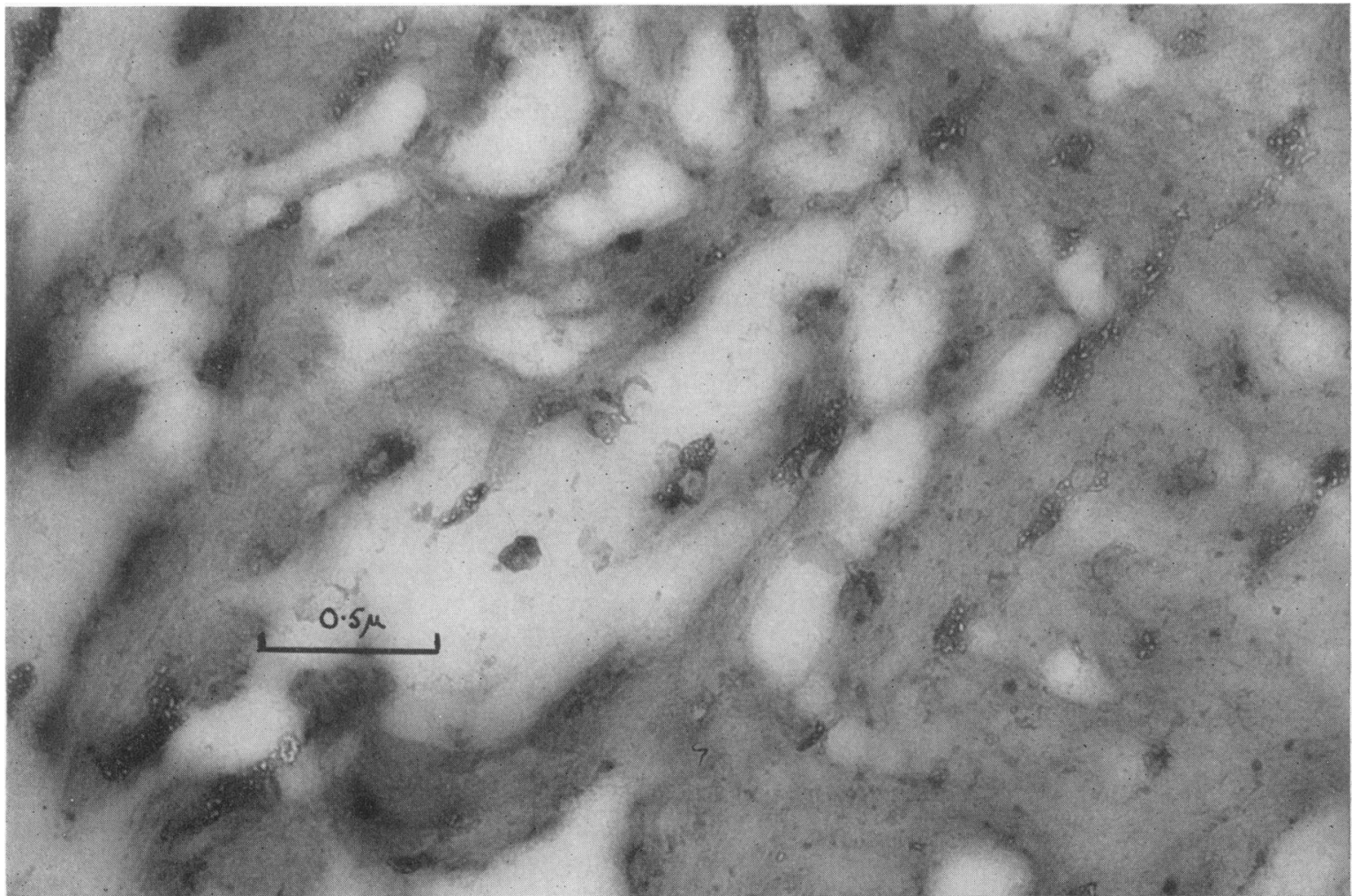

FIG. 5.-Fibrillary material from subendothelial layer of endocardium. See Fig. $3 . \quad \times 45,000$. 


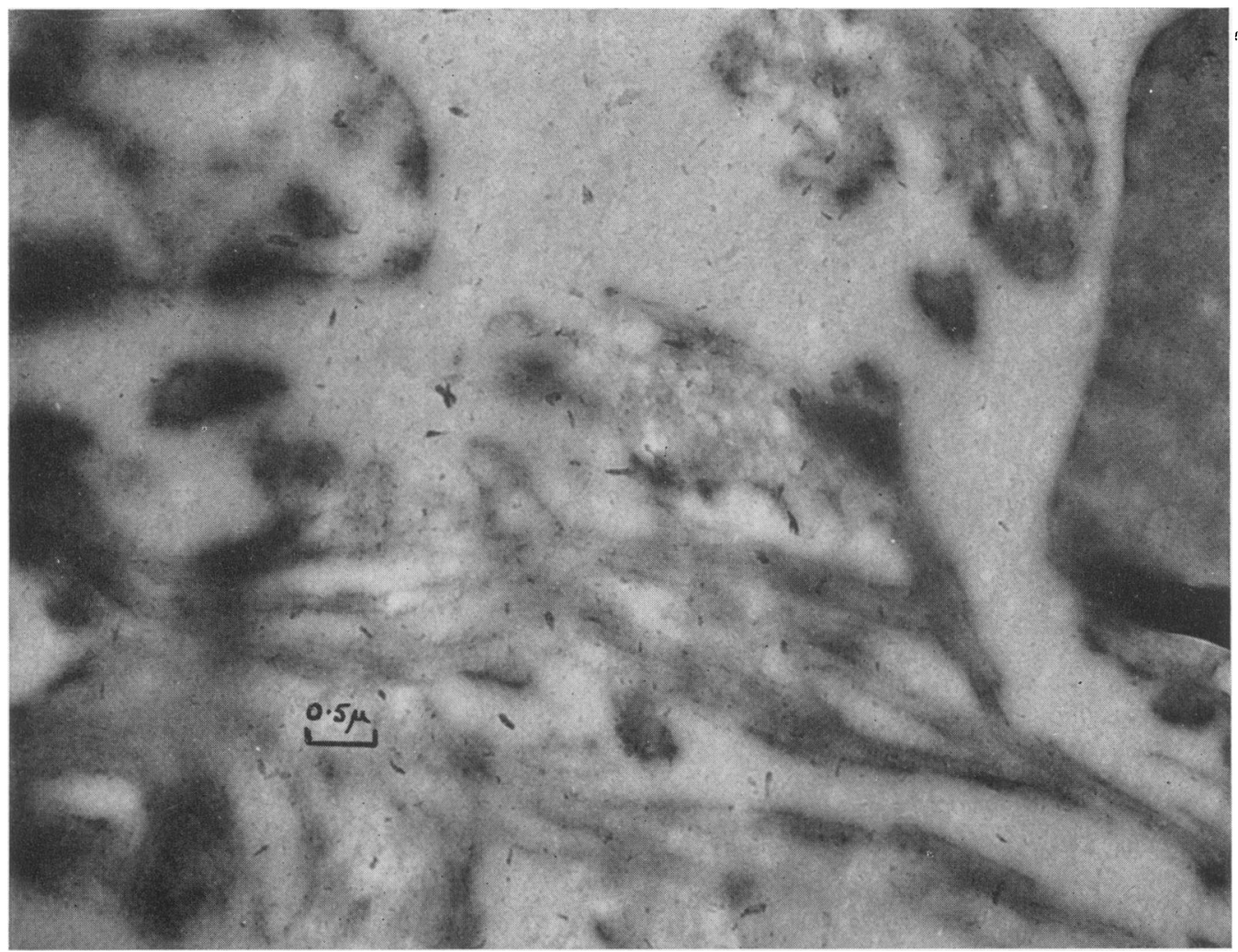

Fig. 6. - Fibrillary material from subendothelial layer. Endothelial cell at top left hand corner. $\times 15,000$.

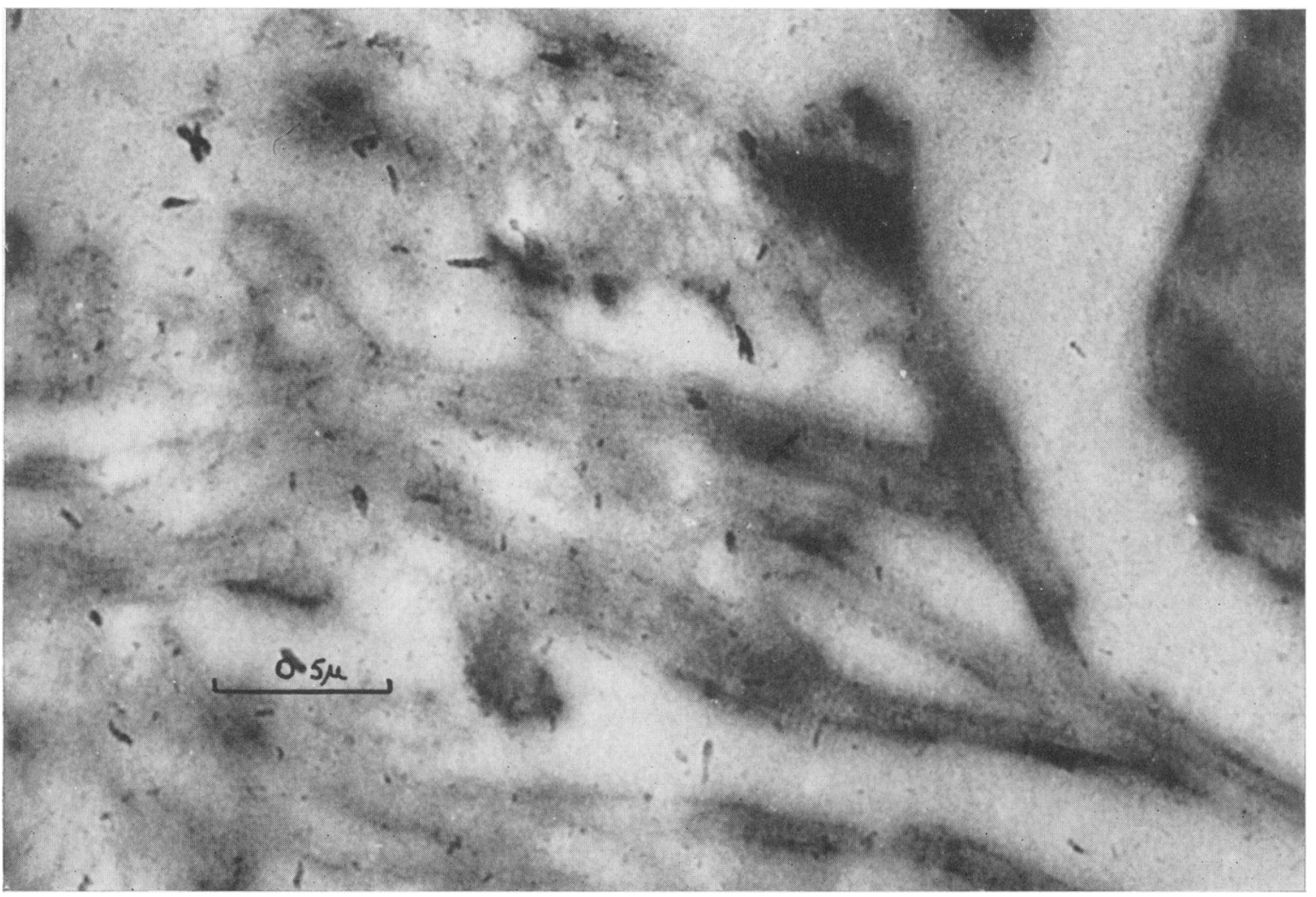

Fig. 7.-Higher magnification of material in Fig. 6. Cross striation at $230 \mathrm{~A}^{\circ}$ intervals present (see Fig. 4). $\times 45,500$. 


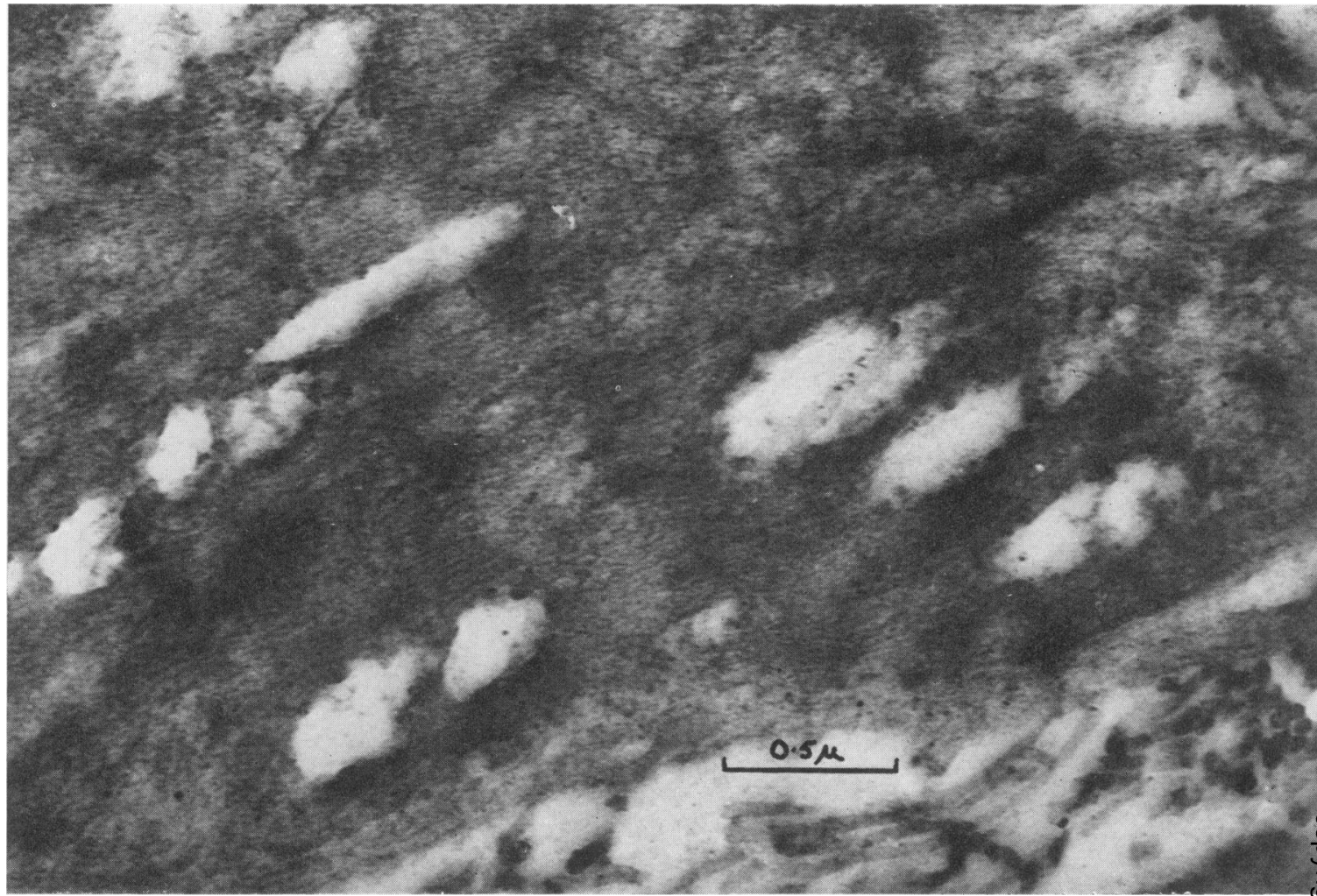

Fig. 8.-Sheet of fibrillary material from subendothelial layer. See Figs. 3 and $5 . \quad \times 45,000$.

(1947) and Hall (1949). The fibrin fibril, about 100 to $150 \mathrm{~A}^{\circ}$ wide, has characteristic periodic cross striations at about $230 \mathrm{~A}^{\circ}$ intervals. Fibrin in ultra-thin sections, however, presents apparently two appearances. Fig. 3 shows the common appearance of fibrin in a thin section from an inflammatory pericardial exudate; the fibrin fibrils, about $200 \mathrm{~A}^{\circ}$ wide, are arranged in small bundles, but there is little or no periodic cross striation to be seen. Fig. 4 shows what is in our experience a relatively uncommon appearance of fibrin, where the periodic cross striations at $230 \mathrm{~A}^{\circ}$ are clearly marked, but no clear fibrillary pattern is present.

\section{Results}

Sectioning of the endocardium from the cases of endocardial fibroelastosis showed that of the seven examples, four contained, in their superficial layers, material bearing a close resemblance to fibrin as seen in the controls. Two others showed in this area material which, although not directly comparable with fibrin, was unlike either elastic tissue or collagen.

Fig. 5, for example, shows material from the subendothelial zone. Here the material is fibrillary and the individual fibrils are, as far as can be judged, about $200 \mathrm{~A}^{\circ}$ wide, and arranged in bundles, but no definite periodic cross striations are present. Figs. 6 and 7 are from the same region in another case. In them, slender branching bundles of fibrillary material are seen just deep to an endothelial cell in the top left hand corner. This material shows both the recognized criteria of fibrin; parts are of a fine fibrillary nature and others show a well marked periodic cross striation at about $230 \mathrm{~A}^{\circ}$ intervals. The latter areas present a close resemblance to the banded appearance of known fibrin as seen in Fig. 4.

In two specimens of endocardium a slightly different type of fibrillary material was found just under the endothelium. This (Fig. 8) is composed of a relatively large sheet of thin $\left(200 \mathrm{~A}^{\circ}\right)$ fibrils lying more or less in parallel with no apparent cross striations. They do, however, bear some resemblance to the individual fibrils of fibrin as seen in Fig. 3 and are unlike collagen fibrils, some of which are seen incidentally in the corner of the section. Sectioning of the endocardium showed that the 
fibrous material we have described was confined to an area just beneath the endothelial cells and it did not appear to be present in the main body of the endocardium, which was composed of collagen and elastic tissue only.

\section{Discussion}

Histologically, the endocardium in endocardial fibroelastosis, including the superficial zones, only gives the staining reactions of collagen and elastic tissue, but electron microscopy shows that at least one other type of fibrous material is present. In this communication and in a previous one, we have put forward the idea that this material may be fibrin, or its derivative, which has become incorporated into the endocardium after surface deposition. Thin sections indicate that the material is situated under the endothelium and that it bears a close resemblance to acknowledged fibrin. The section technique brings out two other points: first, that although the material is less abundant than the teased preparation seemed to suggest, it is still present in considerable amounts, and secondly, that the material is in the form of discrete masses rather than as a continuous layer.

The comparisons we have made are purely morphological, and on these grounds alone we cannot be certain of the identity of the material, but it is clear that it bears little or no resemblance to either collagen or elastic tissue.

\section{Summary}

The endocardium in endocardial fibroelastosis was studied by electron microscopic thin sections. It was found that the fibrillary material just deep to the endothelium resembled fibrin and was dissimilar to both collagen and elastic tissue. This confirmed the results of teased preparation studies.

We wish to thank Professor J. B. Duguid for advice and criticism and Miss Barbara Harris for preparing the enlargements.

REFERENCES

Gross, J. and Schmitt, F. O. (1948). J. exp. Med., 88, 555

Hall, C. E. (1949), J. biol. Chem., 179, 857

Hall, D. A., Reed, R. and Tunbridge, R. E. (1955). Exp. Cell Res. 8, 35 .

Hawn, G. V. Z. and Porter, K. R. (1947). J. exyp. Med., 86, 285.

Still, W. J. S. and Boult, E. H. (1956). Lancet, 2, 117. 